\title{
IMPLEMENTASI TATA LAKSANA PEDOMAN MASTER OF CEREMONY (MC) BAGI SISWA-SISWI SEKOLAH DASAR (Studi Kasus pada Siswa-Siswi Sekolah Dasar Alam Mahira Kota Bengkulu)
}

\author{
Evi Hafizah \\ Jurusan Ilmu Komunikasi, FISIP Universitas Bengkulu \\ Email : evihafizah76@gmail.com
}

Diterima Tangal: 2 Mei 2019

Selesai Tanggal 24 Mei 2019

ABSTRACT

Organizing events / ceremonies has become a part of human daily life related to important events, both with the life of the nation, state, community, organization and family in various types of events for various purposes. During this time the practice of show host was commonly introduced and carried out by adults. Even though for the sake of developing talents, interests and creativity the guidelines for bringing this event are also worthy of being known by children and can be introduced to elementary school age. This will certainly be useful for various activities held by children in their schools and outside schools that require the ability of children to dare to speak in public. The method used is case study. The results and discussion show that the implementation of the Master of Ceremony guidelines for elementary school students includes: MC appearance, MC position, attitudes and ability of $M C$, use of MC language and MC method closed the event in the success of the event.

[Penyelenggaraan acara/upacara sudah menjadi bagian dari kehidupan sehari-hari manusia yang berhubungan dengan peristiwa-peristiwa penting, baik itu dengan kehidupan berbangsa, bernegara, bermasyarakat, berorganisasi maupun berkeluarga dalam berbagai sifat acara untuk berbagai macam tujuan. Selama ini praktek pembawa acara lazim diperkenalkan dan dilakukan oleh orang dewasa. Padahal bagi kepentingan pengembangan bakat, minat dan kreativitas pedoman membawakan acara ini juga layak diketahui oleh anak-anak dan dapat diperkenalkan pada usia sekolah dasar. Hal ini tentunya akan dapat bermanfaat bagi berbagai kegiatan yang diadakan oleh anak-anak di sekolah mereka maupun diluar sekolah yang memerlukan kemampuan anak-anak untuk berani berbicara di depan publik. Metode yang digunakan studi kasus. Hasil dan pembahasan menunjukkan bahwa implementasi tata laksana pedoman Master of Ceremony bagi siswa/siswi sekolah dasar meliputi : penampilan MC, posisi MC, sikap dan daya mampu MC, penggunaan bahasa MC dan cara MC menutup acara dalam menyukseskan acara].

Kata kunci: Pembawa Acara/MC, Anak-anak, Komunikasi Publik

\section{PENDAHULUAN}

Penyelenggaraan acara/upacara

sudah menjadi bagian dari kehidupan sehari-hari manusia yang berhubungan dengan peristiwa-peristiwa penting baik itu dengan kehidupan berbangsa, bernegara, bermasyarakat, berorganisasi maupun berkeluarga dalam berbagai sifat acara untuk berbagai macam tujuan. Oleh karena itu peranan petugas protokol 
sebagai penanggung jawab acara menjadi sangat penting sebagai bagian yang tidak dapat dipisahkan.

Petugas protokol merupakan salah satu kelompok yang menjadi pusat perhatian audiens yang hadir dalam suatu acara/upacara sangat resmi, semi resmi ataupun non resmi, karena ditangan merekalah dapat dipastikan apakah penyelenggaraan acara/upacara tersebut dapat berhasil atau gagal. "Karena tim protokoler merupakan suatu kelompok yang menjadi pusat perhatian, maka penampilan (performance), sikap, etika, bahasa, wawasan, cara berpakaian dan lain-lain juga tidak luput pula menjadi perhatian." 1

Pembawa acara yang lazim kita sebut Master of Ceremony (MC) sebagai salah satu komunikator pada kegiatan keprotokolan, memiliki peran yang menonjol untuk melaksanakan segala sesuatu yang telah dipersiapkan dan direncanakan sesuai karakteristik acara yang akan dibawakan. Pembawa acara dalam kegiatan protokoler bisa disebut sebagai "jantung” acara, dimana dia adalah penentu kelancaran rangkaian acara, mulai

1 Yulianita, Neni.. "Pengantar, Ruang Lingkup, Tugas dan Fungsi Protokoler". Makalah pada Pelatihan Protokoler dan MC UKM PROTOKOLER, (Bandung: Universitas Islam Bandung, 2003), hlm. 1 dan berakhirnya upacara/acara sangat bergantung kepadanya.

$M C$ dipercayakan untuk memimpin upacara/acara sehingga acara atau upacara tersebut berjalan sesuai dengan tujuan yang diinginkan secara tertib, teratur dan rapih, maka dari itu seorang $M C$ memiliki peranan yang sangat penting dalam suatu acara. $M C$ adalah seseorang yang akan memimpin suatu rentetan acara secara teratur dan rapih. Kemampuannya akan sangat menentukan apakah sebuah upacara akan berlangsung lancar atau tersendatsendat. "Sukses/tidaknya suatu upacara/acara sangat ditentukan oleh keberhasilan seorang $M C$ atau pemandu acara/upacara sebagai sub bagian dari tugas-tugas protocol." ${ }^{2}$ Karena itu seorang $M C$ harus benar-benar menguasai seluruh aspek yang akan mempengaruhi kelancaran acara pada saat itu. Ia adalah benar-benar seorang sutradara sebuah acara. Tak ada seorang pejabat penting atau siapapun dapat maju berbicara dihadapan tamu/audiens bila $M C$ tidak mempersilahkannya. Karenanya $M C$ harus tangguh, teguh, bijaksana, cakap dan berwibawa.

2 Yuningsih, Ani. "Panduan Praktis Menyusun Acara dan Menjadi Pemandu Acara (MC)'. Makalah pada Pelatihan Protokoler dan $M C$ UKM PROTOKOLER, (Bandung: Universitas Islam Bandung, 2003), .hlm. 1 
Menyadari akan arti pentingnya seorang $M C$ dalam mensukseskan suatu acara/upacara maka tentunya diperlukan pedoman/panduan khusus bagi $M C$ yang seyogyanya harus dipahami dan diterapkan/diimplemantasikan oleh pembawa acara/MC. Adapun pedoman tersebut meliputi: penampilan, posisi $M C$, penggunaan bahasa, sikap dan daya mampu serta cara $M C$ menutup acara. ${ }^{3}$

Implementasi pedoman $M C$ dalam menunjang kegiatan protokoler yaitu bagaimana seorang pembawa acara/ $M C$ dapat menerapkan petunjuk yang menuntun dirinya agar siap melaksanakan tugas dengan sebaik-baiknya sehingga dapat memuaskan semua orang yang terlibat dalam suatu acara. $M C$ yang tidak memahami dan menerapkan pedoman khusus MC maka akan sulit untuk melaksanakan tugas dengan sukses, bahkan tidak jarang sasaran dari acara yang dilaksanakan sulit mencapai manfaat sesuai dengan aturan yang dikehendaki. Melihat begitu pentingnya peran Master of Ceremony (MC) dalam menyukseskan jalannya suatu acara, maka perlu juga sejak awal disampaikan dan dilatih bagaimana implementasi tata laksana pedoman Master of Ceremony

Januharso, R Trijono, Pedoman Keprotokolan dan Master of Ceremony, (Semarang: Dahara Price, 2003), hlm 27.
(MC) bagi siswa-siswi tingkat Sekolah Dasar sehingga mereka memiliki kemampuan sebagai MC/pembawa acara dengan baik.

Selama ini praktek pembawa acara lazim diperkenalkan dan dilakukan oleh orang dewasa. Padahal bagi kepentingan pengembangan bakat, minat dan kreativitas pedoman membawakan acara ini juga layak diketahui oleh anak-anak dan dapat diperkenalkan pada usia sekolah dasar. Hal ini tentunya akan dapat bermanfaat bagi berbagai kegiatan yang diadakan oleh anak-anak di sekolah mereka maupun diluar sekolah yang memerlukan kemampuan anak-anak untuk berani berbicara di depan publik.

Pembawa acara kategori anak-anak yang berhasil dikenal publik belum banyak, terlebih di Propinsi Bengkulu. Umumnya pembawa acara-anak dilakoni oleh kalangan artis anak yang memang telah memiliki keberanian tampil dimuka publik dan telah banyak dikenal masyarakat, seperti Agnes Monica, Tasya Kamila, Trio Kwek-Kwek sewaktu era tahun 1990-an. Saat ini sudah semakin jarang kita temui MC anak- anak di media massa.

Selayaknya event (acara) anak baik di lingkungan masyarakat maupun di media massa juga dapat dipandu oleh 
anak-anak. Hal ini memberikan tantangan baru bagi pengembangan unsur kreativitas dan keberanian anak Indonesia. Berdasarkan data Global Creativity Index yang dipublikasikan oleh Martin Prosperity Institute tahun 2012, Indonesia menempati peringkat 81 dari 82 negara yang digolongkan kuat secara kreativivitas. ${ }^{4}$ Sebagaimana terlihat pada tabel 1 berikut ini :

\begin{tabular}{|c|c|c|c|c|c|}
\hline 71 & Thalland & 64 & 56 & 67 & 0.220 \\
\hline 73 & Jamaica & 57 & 60 & 71 & 0.215 \\
\hline 74 & Honduras & 58 & 77 & 56 & 0.203 \\
\hline 75 & Nadagascar & 70 & 82 & 40 & 0.199 \\
\hline 76 & Saud Arabia & - & 57 & 79 & 0.191 \\
\hline 77 & Parayay & 71 & 72 & 54 & 0.179 \\
\hline 78 & Iran & - & 71 & $6 B$ & 0.171 \\
\hline 79 & Vet Nam & 68 & 78 & 70 & 0.102 \\
\hline 80 & Pakistan & 73 & 74 & 81 & 0.053 \\
\hline 81 & Indonesia & 74 & 80 & 78 & 0.037 \\
\hline 82 & Canboda & 75 & 81 & 80 & 0.020 \\
\hline
\end{tabular}

sumber: Global Creativity Index 2011

Indeks kreativitas tersebut berkolerasi dengan daya saing negara. Posisi Indonesia dalam daya saing global pun tidak tergolong lebih baik yaitu menempati peringkat ke 46 dari 142 negara berdasarkan Global Competitiveness Report 2011-2012 yang dipublikasikan oleh World Economic Forum. Indeks kreativitas yang rendah tersebut selaras dengan daya saing nasional, terutama pilar

${ }^{4}$ Lihat http://pena.gunadarma.ac.id/indonesia-tidak-kreatif-setuju/ diakses tanggal 20 April 2017. kesiapan teknologi dan pilar inovasi.

Seperti terlihat dalam tabel 2 berikut ini:

\begin{tabular}{|l|c|c|c|c|}
\hline \multicolumn{1}{|c|}{ Negara } & $\begin{array}{c}\text { Peringkat } \\
\text { (dari 142 Negara) }\end{array}$ & Nilai GCl & $\begin{array}{c}\text { Peringkat } \\
\text { 2011-2012 }\end{array}$ & $\begin{array}{c}\text { Peringkat } \\
\text { 2010-2011 }\end{array}$ \\
\hline Singapore & 2 & 5.63 & 2 & 3 \\
\hline Malaysia & 21 & 5.08 & 21 & 26 \\
\hline Brunei Darussalam & 28 & 4.78 & 28 & 28 \\
\hline Thailand & 39 & 4.52 & 39 & 38 \\
\hline Indonesia & 46 & 4.38 & 46 & 44 \\
\hline Vietnam & 65 & 4.24 & 65 & 59 \\
\hline Philippines & 75 & 4.08 & 75 & 85 \\
\hline Cambodia & 97 & 3.85 & 97 & 109 \\
\hline Timor-Leste & 131 & 3.35 & 129 & 133 \\
\hline
\end{tabular}

Sumber : Peringkat Indonesia dibanding negara ASEAN lainnya (Sumber: World Economy Forum)

Unsur kreatifitas yang disandingkan dengan ekonomi sangat sejalan dengan konsep Sekolah Dasar Mahira yang berbasis alam. Sekolah ini memiliki perhatian khusus bagi pengembangan kreativitas dan akhlak anak didiknya. Sekolah ini bertujuan untuk memberi warna baru pada dunia pendidikan yaitu mengkombinasikan pendidikan dan bermain menjadi satu. Orientasi sekolah ini adalah membentuk anak-anak menjadi mandiri dengan semangat wirausaha, sehingga anak-anak dibebaskan untuk bereksplorasi bersama alam sambil mengasah dan mengembangkan kretifitas dengan keahlian wirausaha. Di Sekolah ini anak-anak diajarkan mampu berbisnis dan mengembangkan potensi bakatnya demi 
Evi Havizah:

Implementasi Tata Laksana Pedoman Master Of Ceremony (Mc) Bagi Siswa-Siswi Sekolah Dasar: Studi Kasus Pada Siswa-Siswi Sekolah Dasar Alam Mahira Kota Bengkulu

motif kemandirian ekonomi dan kepemimpinan. ${ }^{5}$

Setiap konsep pengajaran di Mahira didasarkan pada semangat kegembiraan. Tidak boleh ada anak yang tertekan dalam menerima pelajaran. Anakanak diberi kebebasan mengembangkan minat, sehingga sekolah bukan menjadi "pemahat patung" kepribadian anak, melainkan pembangun karakter. Anakanak diberi kebebasan untuk mengembangkan minat dan bakatnya. Mereka juga dapat memilih menjadi apa yang mereka harapkan. Setiap bakat dan potensi anak menjadi perhatian sekolah.

Dengan demikian menarik untuk mengidentifikasikan dan mengetahui Bagaimana implementasi penampilan, posisi, penggunaan bahasa, sikap dan daya mampu Pembawa Acara $/ M C$ dalam menyukseskan acara serta bagaimana implementasi cara pembawa acara/MC menutup acara dalam menyukseskan acara.

\section{KAJIAN TEORITIS}

Dalam setiap acara selalu ada petugas yang disebut pembawa acara atau Master of Ceremony (MC). Tugasnya mengatur pelaksanaan setiap mata acara. Pergantian dari satu mata acara ke mata

\footnotetext{
${ }^{5}$ Lihat http://pedomanbengkulu.com/2015/11/melihat-lebih-dekat-sekolah-alam-mahira/ diakses tanggal 17 April 2017.
}

acara berikutnya menjadi tanggung jawabnya. Orang-orang yang terlibat dalam setiap mata acara itu pun pasti mematuhi perintahnya. Peran yang dimainkann sangat penting. Lancar tidaknya suatu acara sangat tergantung kepintarannya memandu acara.

Pembawa acara sering disebut $M C$ (Master of Ceremony). Kedua istilah ini oleh masyarakat sering dipakai bergantian dengan arti yang sama. Kadang-kadang, mereka menyebut pembawa acara, dan kadang-kadang menyebutnya $M C$. Penyebutan itu tidak selalu salah, tetapi juga tidak selalu benar. Antara keduanya memang terdapat persamaan dan perbedaan. Pembawa acara dapat bertugas dalam acara resmi dan tidak resmi, sedangkan $M C$ hanya bertugas dalam acara tidak resmi. Dengan demikian, dalam acara tidak resmi pemandunya bisa disebut pembawa acara, dan bisa juga disebut $M C^{6}$

Pada hakikatnya pengertian dari Master of Ceremony (MC) adalah seseorang yang memiliki ketrampilan seni dalam bidang improvisasi untuk menghantarkan acara dengan teratur, baik

${ }^{6}$ Wiyanto, Asul dan Astuti, Prima K, Terampil Membawa Acara, (Jakarta: Grasindo. 2002), hlm 2. 
dan memiliki karakteristik yang khas. ${ }^{7}$ Seorang master of ceremony (MC) harus mampu membaca situasi, menciptakan suasana sesuai dengan karakteristik acaranya dan memungkinkan adanya dialog dengan audience.

Pembawa Acara atau Master Of Ceremony sama dengan pemandu upacara/acara (dalam bahasa Indonesia) dapat diartikan sebagai pemimpin upacara/acara yaitu orang yang diberi tugas dan kepercayaan untuk memimpin upacara atau acara, sehingga upacara atau acara berjalan sesuai dengan tujuan yang diinginkan secara tertib, teratur dan rapih. ${ }^{8}$

Adapun fungsi dari $\mathrm{MC}$ itu sendiri yakni orang yang bertugas memandu acara dan bertanggung jawab atas lancar dan suksesnya acara. Seringkali fungsi ini ditampilkan dan diaktualisasikan ketika acara-acara hiburan yang menuntut kreativitas dan improvisasi sesuai dengan jenis acaranya. Memang semua yang dilakukan oleh MC tidak mudah, mengingat tanggung jawabnya terhadap hubungannya dengan image atau citra penyelenggara acara dan kredibilitas seorang MC itu sendiri.

Sebagai refleksi dari makna substansi MC itu sendiri, sedianya ada

7 Rumpoko, Hadi, Panduan pidato dan MC yang memukau, Smart Pustaka, Yogyakarta, 2013), hlm. 90. hlm. 22 . standar yang cocok untuk profesi ini, Di antara standar yang dimaksud, tertuju berdasarkan aspek kepribadian. Kepribadian tersebut antara lain : ${ }^{9}$

1. Ekstrovert, orang-orang yang suka mengekspresikan apa yang dipikirkan, dirasakan, kepada orang lain, artinya orang yang suka memperbincangkan berbagai hal dengan orang lain secara terbuka.

2. Generalis, yaitu orang memiliki banyak pengetahuan umum yang akan memungkinkan dia untuk "bicara apa saja"

3. Fleksibel, yaitu orang yang luwes, mudah menyesuaikan diri dengan situasi.

4. Friendly, yaitu orang yang mudah bergaul dan arena pembawaannya disenangi banyak orang.

Prinsip-Prinsip Dasar $M C$ adalah :

1. Jika acara yang dipandu adalah acara yang bersifat sangat formal, seperti acara kedinasan maka ia tidak perlu membuat improvisasi yang tidak sesuai dengan acara kedinasan.

2. Jika acara yang dipandu bersifat semi formal seperti seminar, maka biasanya ada pemandu acara yang dikenal dengan sebutan pembawa acara dan

\footnotetext{
9 Rumpoko, Hadi, Panduan Pidato...,
} hlm. 92 . 
ada juga pemandu acara yang dikenal dengan sebutan moderator.

3. Jika acara yang dipandu sifatnya informal seperti acara hiburan, ulang tahun, reuni, jumpa langganan dll, maka diperlukan seorang pemandu acara yang pandai berimprovisasi sehingga menarik audience untuk ikut gembira dalam suasana yang hangat dan menyenangkan.

4. Seorang $M C$ adalah komunikator yang mengadakan kontak langsung dengan lawan bicara (audience)nya, oleh karenanya ia harus menguasai ilmu komunikasi khususnya yang berkaitan dengan public speaking, ia harus menguasai psikologi khalayak, bahasa, sosiologi, etika dll.

5. Seorang $M C$ harus mampu mengatasi hambatan-hambatan jalannya acara dan bertanggung jawab penuh atas kelancaran suatu acara yang sedang berlangsung.

6. Seorang $M C$ harus mempersiapkan rencana kerjanya secara matang, dan berkonsentrasi penuh atas apa yang diucapkan ketika sedang memandu acara, baik pemilihan kata, gaya bahasa, maupun diksi dan cara pengucapannya. ${ }^{10}$

10 Yuningsih, Ani. "Panduan Praktis Menyusun ..., hlm. 1.

\section{METODE PENELITIAN}

Paradigma penelitian ini adalah postpositivis dengan pendekatan kualitatif, didasarkan dengan pertimbangan tujuan penelitian (eksplorasi deskripsi) dan juga dikarenakan peneliti ingin mengetahui secara detail tentang bagaimana implementasi tata laksana pedoman Master of Ceremony tentang penampilan MC/pembawa acara, posisi MC/pembawa acara, penggunaan bahasa $\mathrm{MC} /$ pembawa acara sikap dan daya mampu MC/pembawa acara, dan cara MC/pembawa acara menutup acara dalam menyukseskan acara.

Metode yang digunakan dalam penelitian ini adalah studi kasus. Metode penelitian yang digunakan dalam hal ini adalah studi kasus instrinsik dengan alasan bahwa penelitian dilakukan untuk memahami secara utuh kasus implementasi tata laksana pedoman Master of Ceremony yang diperlukan bagi siswa-siswi Sekolah Dasar Alam Mahira Kota Bengkulu tanpa harus dimaksudkan untuk menghasilkan konsep-konsep/teori ataupun tanpa upaya menggeneralisasi. ${ }^{11}$

Data primer dikumpulkan dengan teknik wawancara terhadap perwakilan siswa-siswi kelas 5 dan 6 di Sekolah Dasar

\footnotetext{
${ }^{11}$ Poerwandari, E.K, Penelitian Kualitatif dalam Penelitian Psikologi, (Jakarta: LPSP3, 2001), hlm. 65.
} 
Alam Mahira Kota Bengkulu yang beralamat di Jl. Kinibalu Kebun Tebeng Kota Bengkulu, serta dengan observasi langsung mengamati aktivitas sekolah yang dipandu oleh MC/pembawa acara dari siswa/siswi tersebut yang diadakan oleh Sekolah Dasar Alam Mahira Kota Bengulu. Sedangkan data sekunder adalah berasal dari literatur, rekaman ataupun publikasi dan sebagainya yang mampu mendukung keabsahan data primer baik melalui literatur asli maupun online.

Analisa data dilakukan dengan cara interpretasi melalui pemberian makna berdasarkan hasil diskusi dan tanya jawab dengan beberapa perwakilan siswa-siswi kelas 5 dan 6 di Sekolah Dasar Alam Mahira Kota Bengkulu. Data disajikan dalam bentuk narasi yang disusun secara deskriptif.

\section{HASIL DAN PEMBAHASAN}

Pembawa acara $/ M C$ dituntut untuk mampu membawakan acara secara runtut sesuai dengan karakteristik acara. Demi menjamin kelancaran dan kesuksesan acara yang dibawakan, maka seorang pembawa acara/MC setidaknya perlu mengetahui, memahami serta dapat mengimplementasikan pedoman-pedoman yang dirancang khusus untuk membantu kelancaran pelaksanaan tugasnya.
Berbicara di depan publik atau orang banyak kadangkala membuat seseorang tidak percaya diri akan kemampuannya, begitu juga pada anakanak sekolah dasar. Sebagaimana diakui oleh para siswa/siswi Sekolah Dasar Alam Mahira di Kota Bengkulu, mereka seringkali merasa malu, minder, grogi bila diminta tampil ke depan. Begitu pula jika diminta untuk menjadi Master of Ceremony (MC) dalam acara yang diselenggarakan oleh sekolah. Sekolah Alam Mahira Bengkulu yang bertujuan mengembangkan kreativitas anak didiknya membutuhkan sarana edukasi bagi tujuan tersebut. Sebagaimana dinyatakan salah satu siswa :"walaupun terkadang merasa malu dan grogi bila diminta tampil ke depan khususnya sebagai Master of Ceremony (MC) pada acara kegiatan sekolah tapi tetap mau belajar dan berusaha untuk tampil percaya diri". ${ }^{12}$

Berdasarkan hasil diskusi dan wawancara dengan perwakilan siswa kelas 5 dan 6 di Sekolah Dasar Alam Mahira Kota Bengkulu diperoleh hasil bahwa implementasi tata laksana pedoman Master of Ceremony bagi siswa/siswi sekolah dasar meliputi : penampilan MC/pembawa acara, posisi MC/pembawa acara, sikap dan daya mampu

\footnotetext{
${ }^{12}$ Auzi, Siswa kelas 5 Sekolah Dasar
} Alam Mahira Kota Bengkulu, hasil wawancara tanggal 10 September 2017. 
$\mathrm{MC} /$ pembawa acara, penggunaan bahasa $\mathrm{MC} /$ pembawa acara dan cara MC/pembawa acara menutup acara dalam menyukseskan acara.

\section{Penampilan (Performance) MC}

Dalam tinjauan khusus hal penampilan seorang $M C$ dapat kita perhatikan hal-hal yang mesti dipegang, yaitu:

a. Seorang $M C$ dalam bertugas seyogyanya memakai busana yang wajar, pantas pakai, tidak seronok, harus menyesuaikan dengan sifat acara yang akan dilangsungkan.

b. Sikap tangan dan badan serta kaki sebaiknya selalu terkendali dengan pantas, jangan meletakkan tangan di belakang punggung, di atas pinggang, di dalam saku baju atau saku celana, agar tetap sopan.

c. Tekanan suara seorang $M C$ sebaiknya bisa lantang disertai dengan intonasi yang enak kedengarannya, diucapkan dengan keras (bila perlu gunakan mike/loud speaker) sehingga terdengar ke seluruh hadirin yang ada di ruang/tempat diadakannya acara itu, dengan pengaturan suara secukupnya (tidak terlalu keras dan tidak terlalu kecil volumenya). d. Kendalikan selalu setiap gerakan yang diperlukan dari awal pembukaan sampai selesainya acara itu.

e. Murah senyum, tetapi tetap selalu dijaga kewibawaan dalam artian tidak terlalu banyak senyum terhadap hadirin jika tidak perlu senyum, sehingga akan selalu berkesan fleksibel.

f. Seorang $M C$ pada saat bertugas sebaiknya selalu memegang kertas bertuliskan isi pokok/susunan acara, serta alat tulis seperti ball-point di tangan kanan untuk sewaktu-waktu diperlukan (ada perubahan mata acara, misalnya), hal ini dimaksudkan agar acara yang diselenggarakan tersebut berkesan terencana dangan matang. Sedangkan apabila $M C$ tanpa teks atau kertas berisi coretan dan alat tulis, dengan sendirinya hal ini akan berkesan seolah mengurangi kepercayaan hadirin terhadap $M C$ tersebut, bahkan hadirin akan mengira bahwa acara tersebut dilangsungkan secara mendadak, tanpa rencana matang, ataupun $M C$ yang bertugas disangka kurang siap melaksanakan tugas sebagai pembawa acara. 


\section{Posisi $M C$}

Dalam bertugas, seorang $M C$ tetap berada di sekitar tempat yang khusus diperuntukkan $M C$ (biasanya dilengkapi dengan sebuah meja), jangan turut berada pada barisan hadirin, hal ini tidaklah etis.

\section{Penggunaan Bahasa MC}

a. Gunakan bahasa yang mudah dimengerti, bahasa baku, komunikatif, singkat tetapi jelas, efektif, tanpa banyak basa-basi.

b. Mulailah pada pembukaan acara itu dengan mengucapkan salam pembukaan kepada hadirin, baru kemudian membacakan susunan acara selengkapnya.

c. Pada saat membacakan pergantian acara, maka seorang $M C$ tidak perlu memberikan komentar atas isi sambutan (misalnya pidato pejabat A), melainkan cukup dengan mengucapkan "Demikianlah sambutan dari Bapak... tentang... semoga bermanfaat". Tidaklah pada tempatnya seorang $\quad M C$ mengomentari isi pidato yang baru saja disampaikan oleh penyampai (kecuali bagi sebuah acara hiburan yang pantas untuk dikomentari guna lebih maraknya suasana acara hiburan itu). d. Setiap pergantian mata acara sebaiknya seorang $M C$ memberikan celah waktu untuk mata acara berikutnya (jangan tergesa-gesa dalam membacakannya) melainkan rileks saja tetapi penuh hikmat, meyakinkan.

e. Apabila terdapat kata yang salah ucap, sampaikan kata maaf kepada hadirin, misalnya bila perlu gunakan kata "maksud kami..." (jangan mengulang ucap memakai eh.....aah...oh, seperti "pemula eh pemuka").

f. Kadang $M C$ juga perlu meyampaikan suatu "kesimpulan" atas sebuah sambutan atau acara yang berlangsung, hal ini dimaksudkan untuk memperjelas isi pokok, pesan dan makna mata acara kepada hadirin.

g. Sampaikan kata permohonan maaf atas kekurangan di dalam penyelenggara acara tersebut kepada hadirin dengan penuh rendah hati, tetapi tidak rendah diri.

\section{Sikap dan Daya Mampu Seorang $M C$}

a. Setelah dimulainya acara pertama, seorang $M C$ tidak perlu memberikan jabat tangan kepada tamu utama, pejabat yang memberikan sambutan maupun hadirin, hal ini tidaklah etis 
dilakukan, karena selain membuangbuang waktu, juga $M C$ merupakan personil intern, dianggap sebagai Panitia Pelaksana Upacara/Acara tersebut (kecuali acara selesai).

b. $M C$ harus selalu memusatkan perhatiannya kepada seluruh kegiatan dari awal sampai akhir acara, karena itu di sela-sela acara sebaiknya $M C$ tidak banyak bicara dengan orang yang tidak berkepentingan (kecuali untuk koordinasi dengan pihak-pihak yang terkait, misalnya kepada Kepala Bagian Personalia saat berlangsungnya upacara pelantikan dan serah terima jabatan guna kelengkapan informasi untuk keberhasilan acara tersebut).

c. Jangan menyuarakan bunyi yang tidak enak didengar hadirin, bahkan yang mengagetkan seperti batuk di depan mike dengan kerasnya.

d. $M C$ juga dituntut mampu mengatur peralatan upacara yang diperlukan (paling sedikit menginformasikan tentang tata lampu yang tepat bagi sebuah acara).

e. Seorang $M C$ dituntut pula untuk dapat memecahkan semua masalah, kendala dan hambatan/gangguan yang terjadi pada saat acara berlangsung (misalnya ada suara gaduh dari dalam dan luar ruangan aula, dsb).

f. Ada baiknya $M C$ yang bertugas memandu wisata, tahu keadan lingkungan obyek wisata disertai pemadu wisata resmi (tourist guide) dalam perjalanan tersebut.

\section{Cara $M C$ Menutup Acara}

Sebagai penutup pelaksanaan tugas seorang $M C$, ada berapa hal yang perlu diperhatikan, yaitu:

a. Acara yang berlangsung ditutup dengan kata penutup dari seorang MC utama (biasanya setelah dibacakannya do'a penutup dari pendo'a) dengan mengucapkan:

"Setelah melalui acara demi acara pada upacara ini maka selesailah sudah upacara......(sebutkan nama upacara itu), tak lupa kami yang bertugas (dapat menyebutkan nama $M C$ tersebut) mengucapkan terima kasih atas perhatian hadirin semua, akhir kata wassalamu'alaikum $w r, w b$. Sampai jumpa...."

b. Untuk acara yang dilengkapi dengan hiburan,biasanya dapat pula $M C$ terdiri dari $M C$ utama dan $M C$ (khusus) tambahan (misalnya $M C$ 
khusus pembagi hadiah Juara Cabang Olah Raga, dsb) sehingga suasana akan lebih marak dan menarik. Keuntungan dari $M C$ yang jumlahnya lebih dari satu orang ini adalah selain dapat bertugas secara bergantian, juga dapat saling informasi, koordinasi in-put yang biasanya pada acara yang rumit sifatnya.

c. Seorang $M C$ hanya dapat memberikan komentar terhadap pidato sambutan atau mata acara yang baru usai apabila acara tersebut merupakan hiburan penuh (seperti: pertunjukan lawak, dsb); penobatan sebagai Juara Olahraga dan penyampaian hadiahnya; Pentas Seni; Malam Akrab; Temu Artis; Temu Remaja; Diskusi Panel; Festival Seni; Apresiasi Seni; Relay TV , Radio; dsb. ${ }^{13}$

Pedoman ini sudah dapat diimplementasikan dengan baik oleh siswa/siswi sekolah dasar alam mahira kota Bengkulu ketika dia membawakan suatu acara. MC harus benar-benar menghayati perannya sebagai seorang public speaker.

13 Januharso, R Trijono, Pedoman Keprotokolan..., hlm. 27-31.

\section{KESIMPULAN}

Pembahasan yang telah diurakan terkait dengan implementasi tata laksana pedoman Master of Ceremony bagi siswa/siswi sekolah dasar melaui kegiatan sekolah dapat menumbuhkan rasa percaya diri kepada siswa siswi kelas 5 dan 6 Sekolah Alam Mahira Kota Bengkulu agar lebih berani tampil didepan publik khususnya sebagai MC/pembawa acara. Adapun implementasi tata laksana pedoman Master of Ceremony bagi siswa/siswi sekolah dasar meliputi : penampilan $\mathrm{MC} /$ pembawa acara, posisi MC/pembawa acara, sikap dan daya mampu MC/pembawa acara, penggunaan bahasa MC/pembawa acara dan cara MC/pembawa acara menutup acara dalam menyukseskan acara.

\section{DAFTAR PUSTAKA}

Elly Juniarty dan Pramana, (2006), General Public Speaking: seputar publik speaking, Jakarta: public speaking school

http://pedomanbengkulu.com/2015/11/mel ihat-lebih-dekat-sekolah-alammahira/ diakses tanggal 17 April 2017.

http://pena.gunadarma.ac.id/indonesiatidak-kreatif-setuju/ diakses tanggal 20 April 2017.

Januharso, R Trijono, (2003), Pedoman Keprotokolan dan Master of Ceremony, Semarang, Dahara Price 
Poerwandari, E.K, (2001), Penelitian Kualitatif dalam Penelitian Psikologi, Jakarta, LPSP3

Rumpoko, Hadi, (2013), Panduan pidato dan MC yang memukau, Smart Pustaka, Yogyakarta.

Wiyanto, Asul dan Astuti, Prima K, (2002), Terampil Membawa Acara, Jakarta, Grasindo

Yulianita, Neni. (2003). "Pengantar, Ruang Lingkup, Tugas dan Fungsi Protokoler". Makalah pada Pelatihan Protokoler dan MC UKM PROTOKOLER, Universitas Islam Bandung.

Yuningsih, Ani. (2003). "Panduan Praktis Menyusun Acara dan Menjadi Pemandu Acara (MC)”. Makalah pada Pelatihan Protokoler dan $M C$ UKM PROTOKOLER, Universitas Islam Bandung. 
